\title{
Enkatmetodik -- en svar konst
}

ARTICLE in VÅRD I NORDEN · SEPTEMBER 2005

DOI: $10.1177 / 010740830502500315$

READS

2

2 AUTHORS:

Ulf Jakobsson

Lund University

106 PUBLICATIONS 1,058 CITATIONS

SEE PROFILE

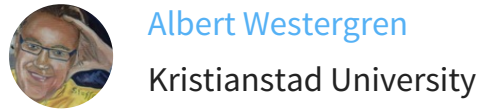

101 PUBLICATIONS 1,087 CITATIONS

SEE PROFILE 